\title{
Uma espécie nova de Anthidianum Michener e notas taxonômicas (Hymenoptera, Megachilidae) ${ }^{1}$
}

\section{Danúncia Urban ${ }^{2}$}

\begin{abstract}
A new species of Anthidianum Michener and taxonomic notes. (Hymenoptera, Megachilidae). Anthidianum andicola sp. n. (from Argentina, Tilcara), is described; a description of the male of Chrisanthidium nigritum Urban, 1997 is presented and Anthidianum bizonatum (Friese, 1925) is considered as junior synonym of Anthidianum subpetiolatum (Schrottky, 1910).

KEY WORDS. Hymenoptera, Megachilidae, Anthidianum, Chrisanthidium, taxonomy
\end{abstract}

O gênero Anthidianum Michener, 1948 era conhecido só pela sua espécietipo, Anthidium subpetiolatum Schrottky, 1910. Neste trabalho apresentamos: 1) a descrição de uma espécie nova, Anthidianum andicola sp. n., proveniente da Argentina, Jujuy, Tilcara; 2) a descrição do macho de Chrisanthidium nigritum Urban, 1997, também coletado na Argentina, Tilcara; 3) Anthidium bizonatum Friese, 1925, um novo sinônimo júnior de Anthidianum subpetiolatum (Schrottky, 1910). Os gêneros Chrisanthidium Urban, 1997 e Anthidianum Michener, 1948 têm em comum, a ausência da carena entre a face anterior e a lateral dos mesepisternos.

\section{Anthidianum andicola sp. $\mathbf{n}$.}

Figs 1-2

Diagnose. Três faixas amarelo-pálidas no metasoma, macho com desenhos amarelos na cabeça.

Holótipo macho. Tegumento predominante preto exceto: clípeo, parte inferior das paroculares, área supraclipeal e minúsculas nódoas acima dos olhos amarelo-esbranquiçadas. Nas paroculares a mácula amarela até a sutura epistomal e parte adjacente da sutura subantenal, a partir daí estreitando gradativamente, a ponta dorsal sub-truncada ao nível do terço superior dos olhos. Antenas ferrugíneas, menos na parte dorsal, a partir do terceiro flagelômero, onde passam a castanho-escuras. Mesoscuto com faixas amarelo-esbranquiçadas largas nos cantos basais. Tégulas e base das asas ferrugíneas, dois terços apicais das asas com tingimento enegrecido. Pernas ferrugíneas das tíbias aos tarsos; nos fêmures anteriores, o ferrugíneo ocupando mais da metade do seu comprimento, nos medianos só o terço apical e, nos posteriores, a ponta. Do segundo ao quarto tergo com faixa discal amarelo-esbranquiçada.

1) Contribuição número 1202 do Departamento de Zoologia, Universidade Federal do Paraná.

2) Departamento de Zoologia, Universidade Federal do Paraná. Caixa Postal 19020, 81531-990 Curitiba, Paraná, Brasil. Bolsista do CNPq. 
Pilosidade negra, longa e densa. Sétimo tergo com quatro projeções dentiformes delgadas, as duas medianas longas como os distitarsos e as laterais muito curtas.

Comprimento $9,25 \mathrm{~mm}$; comprimento da asa a partir do esclerito costal $7,25 \mathrm{~mm}$; largura da cabeça $2,96 \mathrm{~mm}$.

Alótipo fêmea. Assemelha-se ao macho quanto ao mesosoma e metasoma. Cabeça preta com minúscula nódoa amarela acima dos olhos.

Comprimento $9,83 \mathrm{~mm}$; comprimento da asa a partir do esclerito costal $8,25 \mathrm{~mm}$; largura da cabeça $3,44 \mathrm{~mm}$.

Holótipo macho. ARGENTINA, Jujuy: Tilcara (Toma de Água, 2900m), J.L. Neff leg., 25.I.1977. Alótipo com os mesmos dados do holótipo. Depositados na Coleção de Entomologia J.S. Moure, Departamento de Zoologia, Universidade Federal do Paraná (DZUP).

Etimologia. Nome específico significando habitante dos Andes.

\section{Anthidianum subpetiolatum (Schrottky, 1910)}

\section{Fig. 5}

Anthidium subpetiolatum Schrottky, 1910: 269.

Anthidium bizonatum Friese, 1925: 42. Syn. n.

Trichanthidium subpetiolatum; Moure, 1947: 20.

Allanthidium (Anthidianum) subpetiolatum; Michener, 1948: 13.

Allanthidium (Anthidianum) bizonatum; Toro \& Rodríguez, 1998: 66.

Anthidianum subpetiolatum; Urban, 1999: 164.

O lectótipo fêmea de Anthidium subpetiolatum Schrottky, 1910, foi examinado, está depositado no Museu de Zoologia da Universidade de São Paulo. O tipo macho de Anthidium bizonatum Friese, 1925, não foi visto; a sinonímia foi feita com base na descrição original.

Comentários. Espécie reconhecida, à primeira vista, por ter apenas duas faixas amarelas no metasoma. $\mathrm{O}$ macho tem o tegumento quase inteiramente preto na cabeça, apenas duas nodoazinhas amareladas acima dos olhos e as projeções dentiformes laterais do sétimo tergo são pouco menores que as medianas.

Distribuição geográfica. BolíviA, Oruro (localidade-tipo de A. bizonatum) [3800 m]; Cochabamba, Tiraque, $3200 \mathrm{~m}$. ARgENTINA, Catamarca (localidade-tipo de A. subpetiolatum); Tucumán, Nevados de Aconquija, Quebrada del Duero, 4000m; Nevados de Aconquija, Cueva del Overo. ChILE, Arica, Putre, $2000 \mathrm{~m}$.

\section{Chrisanthidium nigritum Urban, 1997}

\section{Figs $3-4$}

Chrisanthidium nigritum Urban, 1997: 184.

Macho. Tegumento predominante preto; amarelo-esbranquiçado no clípeo, área supraclipeal e parte das paroculares; nas paroculares inferiores a mácula até pouco abaixo dos alvéolos, ai com recorte quase reto, diminuindo gradualmente até o terço dorsal dos olhos; na supraclipeal o amarelo com o contorno dorsal fracamente 

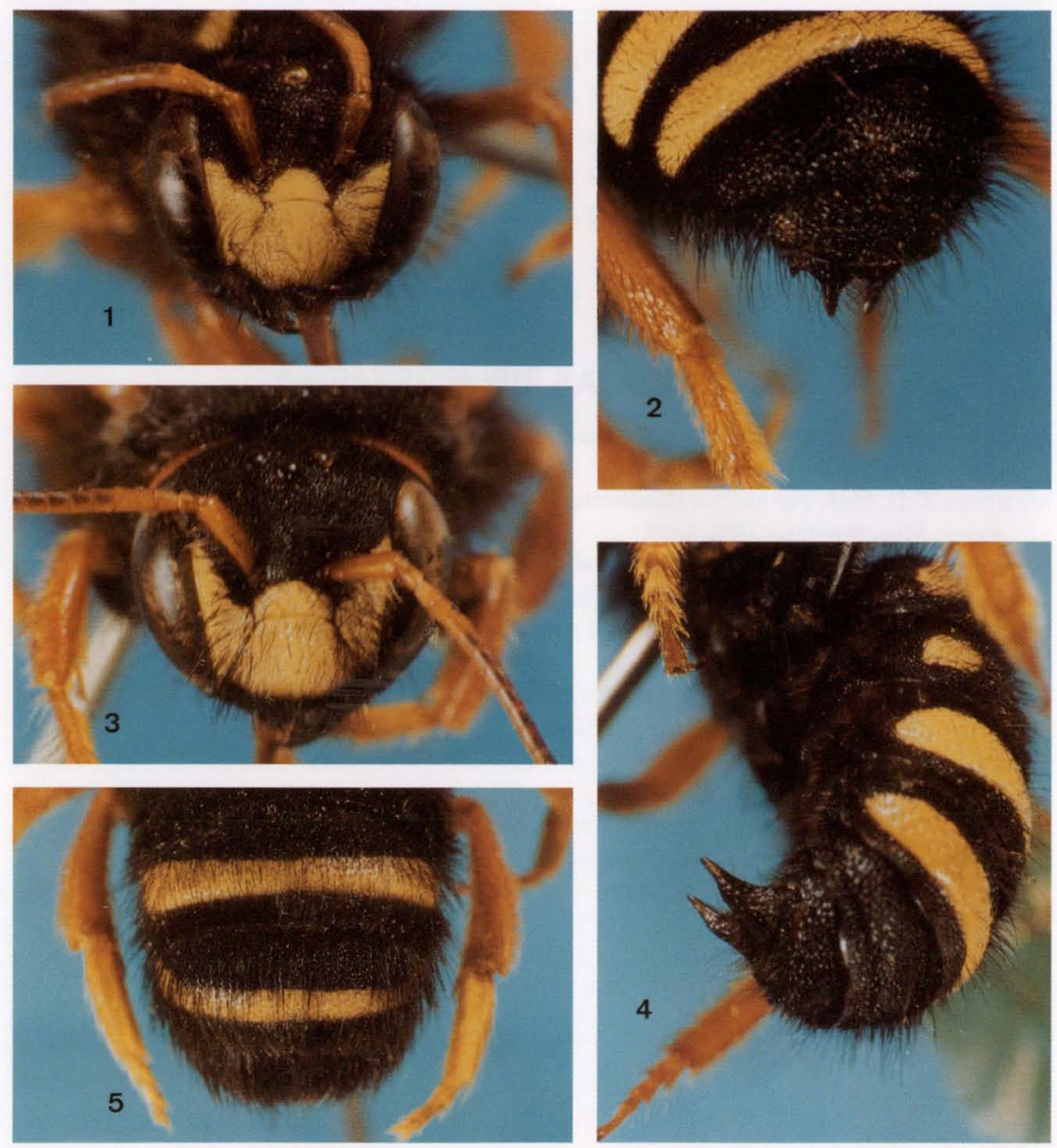

Figs 1-5. Anthidianum andicola sp. n. holótipo macho: (1) cabeça, (2) parte distal do metasoma; Chrisanthidium nigritum, macho: (3) cabeça, (4) metasoma; Anthidianum subpetiolatum: (5) vista dorsal do metasoma do macho.

anguloso; duas nódoas grandes ferrugíneas acima dos olhos, mais estreitas em direção ao meio, como na fêmea; antenas ferrugíneas. Mesosoma sem máculas pálidas; tégulas ferrugíneas, pernas ferrugíneas do ápice dos fêmures aos tarsos; asas tingidas com ferrugíneo no terço basal, o restante enegrecido. Primeiro e segundo tergos com nódoas laterais amarelo-esbranquiçadas, maiores no primeiro; terceiro e quarto tergos com faixa larga amarelo-esbranquiçada. Faixas amarelo-pálidas do terceiro e quarto tergos com o tegumento brilhante e liso, pontos esparsos.

Sétimo tergo como em Chrisanthidium bidentatum (Friese, 1908), com dois processos apicais cônicos.

Comprimento $9,75 \mathrm{~mm}$; comprimento da asa a partir do esclerito costal $8,75 \mathrm{~mm}$; largura da cabeça $3,12 \mathrm{~mm}$. 
Material examinado: ARgENTINA, Jujuy: Tilcara (2900 m), macho e fêmea. Comentários. A espécie foi descrita com base em um exemplar fêmea. Pela primeira vez foi examinado um macho, coletado por J.L. Neff na localidade-tipo, em janeiro de 1977. O macho de Chrisanthidium bidentatum tem porte menor que o de Chrisanthidium nigritum, faixas amarelas laterais do primeiro ao terceiro tergo e o tergo distal ferrugíneo.

Agradecimentos ao Prof. Dr. Albino Morimasa Sakakibara pelas fotos que ilustram o trabalho.

\section{REFERÊNCIAS BIBLIOGRÁFICAS}

FrIESE, H. 1925. Neue Formen von Schmarotzerbienen, besonders aus den paläarktischen Gebiet.

Konowia 4: 27-42.

MiCHENER, C.D. 1948. The generic classification of the Anthidiine bees (Hymenoptera, Megachilidae). Amer. Mus. Novitates 1381: 1-29.

MouRE, J.S. 1947. Novos Agrupamemtos genéricos e algumas espécies novas de abelhas sulamericanas.

Publ. Avuls Museu Paranaense, Curitiba, 3: 1-37.

SCHRottky, C. 1910. Neue südamerikanische Arten der Bienengattung Anthidium Fabr. Wien ent. Ztg. 29 (7-8): 267-271.

Toro, H. \& S. Rodríguez, 1998. Los Anthidiini de Chile: Clave para especies (Himenoptera: Megachilidae). Acta Ent. Chilena 22: 63-78.

UrBan, D. 1997. Chrisanthidium, um novo gênero sulamericano de Dianthidiini (Hymenoptera, Megachilidae). Revta bras. Zool. 14 (1): 181-185.

. 1999. Gênero novo e espécies novas de Anthidiinae e nota taxonômica (Hymenoptera, Megachilidae). Acta. Biol. Par., Curitiba, 28 (1, 2, 3, 4): 159-167.

Recebido em 16.III.2000; aceito em 07.IV.2001. 